Carmen Teresa Gabriel Anhorn

\title{
UM OBJETO DE ENSINO CHAMADO HISTÓRIA A disciplina de história nas tramas da didatização
}

Tese de Doutorado

Tese apresentada ao Programa de Pós-graduação em Educação do Departamento de Educação da PUC-Rio como parte dos requisitos parciais para obtenção do título de doutor em Educação.

Orientadora: Vera Maria Candau

Volume I

Rio de Janeiro

Maio de 2003 
Carmen Teresa Gabriel Anhorn

\title{
UM OBJETO DE ENSINO CHAMADO HISTÓRIA A disciplina de história nas tramas da didatização
}

Tese apresentada como requisito parcial para obtenção do grau de Doutor pelo Programa de Pósgraduação em Educação do Departamento de Educação do Centro de Teologia e Ciências Humanas da PUC-Rio. Aprovada pela Comissão examinadora abaixo assinada.

\author{
Prof. Vera Maria F. Candau \\ Orientadora \\ Departamento de Educação - PUC-Rio \\ Prof. Creso Franco \\ Departamento de Educação - PUC-Rio
}

Prof. IImar Rohloff de Mattos Departamento de História - PUC-Rio

Prof. Alice Ribeiro Casimiro Lopes

UFRJ

Prof. Anna Maria Salgueiro Caldeira
PUC-BH

Prof. Jürgen Heye

Coordenador Setorial do Centro de Teologia e

Ciências Humanas 
Todos os direitos reservados. É proibida a reprodução total ou parcial do trabalho sem a autorização da universidade, da autora e da orientadora.

\section{Carmen Teresa Gabriel Anhorn}

Formada em Historia pela Universidade Federal Fluminense (UFF) em 1980. Pós-graduada em Estudos do Desenvolvimento e Subdesenvolvimento pelo IUED de Genebra (Suíça). Obteve o título de Mestre em Educação na PUC-Rio em 1999. Trabalhou na área de formação de professores de História no Instituto Superior de Educação da República de Cabo Verde. Professora de História do Ensino Fundamental e do Ensino Médio. Professora de Didática e Metodologia do Ensino de Ciências Sociais em cursos de Pedagogia e Licenciatura. Trabalha na área de formação continuada de professores. Autora de livros didáticos e paradidáticos no âmbito da História.

Ficha Catalográfica

Anhorn, Carmen Teresa Gabriel
Um objeto de ensino chamado História; A disciplina de
História nas tramas da didatização/ Carmen Teresa Gabriel
Anhorn; orientadora: Vera Maria Candau. - Rio de Janeiro:
PUC, Departamento de Educação, 2003.
II v., 403 f; $29,7 \mathrm{~cm}$
1. Tese (doutorado) - Pontifícia Universidade Católica do
Rio de Janeiro, Departamento de Educação.
Inclui referências bibliográficas.
1. Ensino de história. 2. Epistemologia escolar. 3.
Transposição didática. 4. Noosfera. 5. Saber escolar. 6. Saber
acadêmico. 7. Saber ensinado. 8. Saber a-ser-ensinado. 9.
Currículo. 10. Identidade nacional I. Anhorn, Carmen T. G.
(Carmen Teresa Anhorn). II. Pontifícia Universidade Católica
do Rio de Janeiro. Departamento de Educação III. Um objeto
de ensino chamado História; A disciplina de História nas
tramas da didatização.




\section{Agradecimentos}

A minha orientadora, Professora Vera Maria Candau pelo estimulo e pela confiança na realização deste trabalho.

Aos meus colegas e professores do Programa de Pós-graduação em Educação da PUC-Rio pelo incentivo constante ao longo dessa caminhada.

Aos professores que participaram da banca examinadora.

A CAPES, FAPERJ e a PUC-Rio, pelos auxílios concedidos, sem os quais esse trabalho não poderia ter sido realizado.

As professoras que me permitiram que suas aulas fossem observadas e aos autores do PCN de história entrevistados sem os quais esta pesquisa não existiria.

As colegas de profissão Ana Maria Monteiro e Mirian Leite pela escuta aguçada e pelo olhar crítico cujas contribuições foram de enorme valia para as minhas reflexões.

A Alain que me faz todo dia acreditar que a vida vale a pena de ser vivida.

Aos meus filhos Sarah, Maïra, Pedro e Nara que não me deixam esquecer que a vida é bonita e pela paciência por tantas horas em que estive indisponível para eles.

A Diego, meu neto, por lembrar que a vida é um eterno recomeçar.

Aos meus pais pelos valores que me passaram.

A todos os amigos e familiares que de uma forma ou de outra me estimularam e me ajudaram. 


\section{Resumo}

Anhorn, Carmen Teresa Gabriel; Candau, Vera Maria. Um objeto de ensino chamado História: A disciplina de história nas tramas da didatização. Rio de Janeiro, 2003. 403p. Tese de Doutorado Departamento de Educação, Pontifícia Universidade Católica do Rio de Janeiro.

Inserido no campo da reflexão didática da História e tendo como base as contribuições da teoria da transposição didática desenvolvida no programa de pesquisa de Yves Chevallard, este estudo tem como preocupação central analisar a especificidade do processo de didatização que permite que a História de objeto de investigação acadêmica transforme-se em objeto de ensino de uma disciplina escolar. Em função da natureza epistemológica do saber em foco, foram selecionados três grandes eixos de discussão - didática e epistemologia; epistemologia e linguagem e identidade e narrativa - a partir dos quais emergiram os demais enfoques que contribuíram para a construção do quadro teórico-metodológico desta pesquisa. Apoiada nas contribuições da epistemologia escolar na perspectiva chevalardiana, da proposta de Análise de Discurso de Fairclough e da hermenêutica de Ricoeur procurei trazer à tona a dinâmica específica da vida dos saberes históricos escolares nas duas esferas de didatização selecionadas (PCN de história e sala de aula) Conceitos como identidade narrativa (Ricoeur), prática discursiva (Fairclough), campo de experiência e horizonte de expectativa (Koselleck) ocupam assim, um lugar de destaque nessa reflexão na medida em que oferecem pistas alternativas para enfrentar a necessária transposição do saber histórico sem negar, contudo a sua complexidade. $O$ primeiro conceito ajuda a pensar a problemática da construção da identidade nacional, uma das principais "razões de ser" do saber histórico tendo incidência direta sobre a sua natureza epistemológica. $O$ segundo aponta pistas metodológicas fecundas para a apreensão das dimensões axiológicas do objeto saber, central nesta pesquisa. Quanto aos conceitos elaborados por Koselleck, eles permitem enfrentar a questão do tempo histórico, crucial na reflexão histórica, sem cair em visões dicotômicas. O objetivo maior deste estudo é contribuir para a superação de alguns desafios situados no campo do ensino de história referentes à problemática dos saberes. Ao reconhecer a relevância e complexidade do elemento saber no processo de ensino-aprendizagem, oferece a possibilidade de ampliar o leque das variáveis que entram, ou devem entrar em jogo, na avaliação das permanências e mudanças do saber histórico "a-ser-ensinado" e "ensinado" ao longo da trajetória de construção dessa disciplina.

\section{Palavras Chave}

Ensino de história; epistemologia escolar; transposição didática; noosfera; saber escolar; saber acadêmico; saber ensinado; saber a-ser-ensinado: currículo real; currículo formal; prática discursiva; tempo histórico; identidade narrativa; identidade nacional. 


\section{Résumé}

Anhorn, Carmen Teresa Gabriel; Candau, Vera Maria. Un objet d'enseignement appelé Histoire: La discipline de l'histoire dans les trames de la didactisation. Rio de Janeiro 2003. 403p. Thèse de Doctorat Departamento de Educação, Pontifícia Universidade Católica do Rio de Janeiro.

Cette étude s'insère dans le champ de la réflexion didactique se rapportant à l'Histoire et s'appuie sur les contributions de la théorie de la "transposition didactique" développée par Yves Chevallard dans son programme de recherche. Elle a comme préoccupation centrale l'analyse de la spécificité du processus de didactisation, qui permet à l'Histoire, objet de recherche académique, de se transformer en objet d'enseignement d'une discipline scolaire. En fonction de la nature épistémologique particulière du savoir historique, j'ai retenu trois grands axes de discussion -didactique et épistémologie, épistémologie et langage et enfin identité et récit- à partir desquels ont émergé les autres approches qui ont contribué à la construction du cadre théorique et méthodologique de ma recherche. En m'appuyant sur les contributions de l'épistémologie scolaire dans la perspective de Chevallard, sur celles de la proposition d'Analyse du Discours de Fairclough et enfin sur celles de l'herméneutique de Ricoeur, j'ai tenté de faire apparaître la dynamique spécifique de la vie des savoirs historiques scolaires dans les deux sphères de didactisation choisies (PCN d'Histoire et salle de classe). C'est ainsi que des concepts tels qu'identité narrative (Ricoeur), pratique discursive (Fairclough), champ d'expérience et horizon d'expectative (Koselleck), occupent une place prééminente dans cette réflexion, dans la mesure où elles offrent des pistes alternatives pour affronter la nécessaire transposition du savoir historique sans nier, cependant, sa complexité. Le premier concept aide à penser la problématique de la construction de l'identité nationale, une des principales raisons d'être du savoir historique et qui a une incidence directe sur sa nature épistémologique. Le second concept montre des pistes méthodologiques fécondes pour l'appréhension des dimensions axiologiques de l'objet savoir, central dans cette recherche. Quant aux concepts élaborés par Koselleck, ils permettent d'affronter la question du temps historique -crucial dans la réflexion sur cette discipline- sans tomber dans des visions dichotomiques. L'objectif majeur de ce travail est donc de contribuer à surmonter quelques défis liés à la problématique du savoir et situés dans le champ de l'enseignement de l'Histoire. Il a comme base une approche qui, en reconnaissant l'importance et la complexité de l'élément savoir dans le processus d'enseignement-apprentissage, offre la possibilité d'amplifier l'éventail des variables qui entrent, ou qui devraient entrer, en jeu, quand il s'agit d'évaluer le savoir historique "à enseigner" ou "enseigné", tout au long de la trajectoire de construction de cette discipline .

\section{Mots-Clé}

Enseignement de l'Histoire; épistémologie scolaire; transposition didactique; noosphère; savoir scolaire; savoir académique; savoir enseigné, savoir à enseigner; curriculum réel; curriculum formel; pratique discursive; temps historique; identité narrative; identité nationale 


\section{Sumario}

1. INTRODUÇÃO: A tela de fundo da trama 11

2. Saberes, narrativas e identidades: fios da trama 26

3. Didática e epistemologia $\quad 29$

3.1. A ênfase na problemática dos saberes escolares:

diferentes olhares $\quad 30$

3.2. A reflexão epistemológica na teoria da transposição didática: o olhar privilegiado

4. Epistemologia e linguagem 76

4.1.Os saberes como práticas discursivas $\quad 82$

4.2.O saber histórico e a questão da linguagem 92

5. Identidade(s) e narrativas(s) 124

5.1. A identidade na berlinda 131

5.2. História, memória e identidade 140

5.2.1. No terreno das concepções historiográficas 141

5.2.2. Nação e nacionalismos em debate 142

5.2.3. Memória e história em questão 149

5.3. Identidade narrativa: entre tradição e tradução 154

6. Costurando os fios 159

7. Nas tramas da didatização 167

8. No domínio da transposição 172

8.1. Da "razão de ser" do saber ao "objeto de saber" em História 172

8.2. Noosfera: um elo importante no processo de didatização 184

8.3. Sala de aula: a transposição interna 193

8.3.1. Funcionamento didático e transposição interna 193

8.3.2. Sobre as aulas observadas 198 
9. Os PCN's de História: um exemplo de noosfera em ação 205

9.1. Uma disciplina em crise? 209

9.2. PCN de história:

um elo na cadeia de comunicação e de transposição 218

9.2.1. Uma combinação de diferentes textos 221

9.2.2. Em busca da superação de antigos problemas 223

9.2.3. Proposta ambígua de um novo texto do saber 233

9.2.4. Quem narra e quem faz essa história? 235

9.2.5. Do ensino da História tradicional ao ensino de muitas histórias 239

9.3. A busca do reequilíbrio: entre a busca da compatibilidade externa e a necessária adequação interna 242

9.3.1. Em busca da compatibilidade externa 243

9.3.2. O fluxo dos saberes vindos de Academia 244

9.3.3. A procura da distinção: o distanciamento em relação aos saberes do senso comum 251

9.3.4. A necessária adequação interna 252

9.3.5. Eixos temáticos : uma opção didática? 257

9.3.6. Eixos temáticos e processos de textualização 259

9.4. Diferentes vozes: entre permanências e mudanças 264

10. A Narrativa da brasilidade nas tramas do PCN de História 271

10.1. O lugar atribuído à História do Brasil 273

10.2. A questão da(s) identidade(s) no PCN de História 283

10.2.1. A identidade como fio narrador da história narrada 285

10.2.2. Um tema negociado / um tema conflituoso 289

10.2.3. Identidade nacional x outras identidades 290

10.2.4. De objetivo de ensino a objeto a ser ensinado 293

10.3. A Independência do Brasil: entre temas e tramas 296

10.3.1. "Temas clássicos", "grandes temas", "conteúdos mínimos": o que ensinar? 298

10.3.2. Entre o dever de memória e a reflexão crítica 300

10.3.3. A Independência do Brasil entre o antigo e o novo texto do saber 303

10.3.4. Construindo a identidade narrativa do brasileiro 305 
11. Narrativas da Brasilidade na sala de Aula 309

11.1. As aulas de história: uma superposição de narrativas 310

11.2. Professores leitores $\quad 314$

11.2.1. Leitores possíveis do PCN de História 316

11.2.2. A transposição interna do combate à história tradicional 320

11.2.3. O presente como ponto de partida 321

11.2.4. A busca do sentido: o risco de perder o fio da meada 322

11.3. Brasilidade narrada em atos 324

11.3.1. Nos bastidores das cenas 338

12. CONSIDERAÇÕES FINAIS: Entre remates e alinhavos 347

13. Referências bibliográficas 357

14. ANEXOS 384 